\title{
nD modelling: industry uptake considerations
}

\author{
A. Lee \& M. G. Sexton \\ Research Institute for the Built \& Human Environment, University of Salford, UK
}

Case study

\section{Purpose}

$\mathrm{nD}$ modelling technology ushers in novel possibilities to transform the design, production and use of buildings by providing a ‘... multi-dimensional model ... [which] ... enables true what-if analyses to be performed to demonstrate the real cost in terms of the design issues ... [and] ... the trade-offs between the parameters ... clearly envisaged' (Lee, et al., 2003: 5). The espoused benefits of a new technology such as $\mathrm{nD}$ modelling, however, are not sufficient in itself to ensure its widespread adoption and use within the construction industry. Technology transfer is widely considered to be a potentially powerful mechanism to provide the construction industry with new technologies that can, where appropriate, transform and complement current technologies to create and sustain better levels of performance (DTI, 2002; Mitropoulos and Tatum, 1999; DETR, 1998). This paper aims to identify the key enablers and obstacles to the effective adoption and use of nD modelling technology.

\section{Methodology/approach}

This paper explores the feasibility of industry absorbing and diffusing nD modelling technology by considering key technology transfer issues; namely organisational direction, interorganisational networks, and knowledge characteristics of technology. Findings from semi- 
structured interviews around a diagnostic technology transfer framework are used to offer implications for theory and practice.

\section{Findings}

The results from 15 survey interviews indicate that construction professionals appreciate the potential significant benefits of $\mathrm{nD}$ modelling technology, but at present, $\mathrm{nD}$ modelling technology is seen as too embryonic; too far removed from construction firms' 'comfort zones'; requiring too much investment; and, containing too many risks.

\section{Practical implications}

The paper concludes that the challenge for $\mathrm{nD}$ modelling technology, along with any new technology, is to shift from its 'technology push' emphasis to a more balanced 'market orientated' stance which allows the technology to be shaped by both strategic design concerns, and the rough and tumble of day-to-day operational needs. If this trajectory is pursued, $\mathrm{nD}$ modelling technology has a positive future.

Keywords: $\mathrm{nD}$ modelling, technology transfer, building information model, innovation, IT (information technology)

\section{Introduction}

A construction project team is characterised by many professionals from various disciplines. The central ambition for this team is to satisfy all stakeholder requirements in order to generate a mutually beneficial solution. This idealised aim requires appropriate integration of project information; however, this is difficult to achieve due to the constraints and conflicts upon the 
construction team imposed by the number and variety of social, economic and legislative factors; different epistemological perspectives and methods; and, the personal requirements and agendas of the various stakeholder groups. Thus, one of the main challenges facing the construction project team is how to improve the efficiency and effectiveness of the integrated design and construction process. Moreover, can a more effective use of information technology (IT) achieve this? A concept that has recently been proposed as a solution to solve the ills of coordination, communication and reconciliation of diverse stakeholder requirements is $\mathrm{nD}$ modelling.

An $\mathrm{nD}$ model is an extension of the building information model, which incorporates multiaspects of design information required at each stage of the lifecycle of a building facility (Lee et $\mathrm{al}, 2003) . \mathrm{nD}$ is unlike traditional 2D and 3D CAD (computer aided design) systems where the building design is represented in multiple files made up of lines, arcs and circles, and the building information is contained within several document formats such as spreadsheets and word processing files. An nD database is constructed with intelligent 'objects' which represent building elements, such as walls, doors and windows. From this central database, different views of the information can be generated automatically; views that correspond to traditional design documents; for example, plans, sections, elevations and schedules. As the documents are derived from the same central database, they are all coordinated and accurate - any design changes made in the central model will be automatically reflected in the resultant drawings, ensuring a complete and consistent set of documentation (Graphisoft, 2003).

This paper explores the feasibility of industry absorbing and diffusing the $\mathrm{nD}$ modelling technology by considering key technology transfer issues. Technology transfer is widely considered to be a potentially powerful mechanism to provide the construction industry with 
new technologies that can, where appropriate, transform and complement current technologies to create and sustain better levels of performance (DTI, 2002; Mitropoulos and Tatum, 1999; DETR, 1998). Commentators, however, have noted that the construction sector often lags behind other industries in technology adoption (for example, see Sexton \& Barrett, 2004; Fairclough, 2003; Sauer, et al., 1999). We understand effective technology transfer as being the 'movement of know-how, technical knowledge, or technology from one organizational setting to another' (Roessner in Bozeman, 2000, p. 629). This 'movement' is driven by a combination of actors' unique needs (Klien and Crandell, 1991) and tacit knowledge (Teece, 1977; Howells, 1996). The barriers to the diffusion of new construction technologies are reinforced by, among other issues, lack of information for relevant construction actors regarding technologies' characteristics and appropriate uses (Sexton \& Barrett, 2004; NAHB, 2001; Anumba, 1998). Within this context, the paper is structured as follows. First, the nD modelling concept is further developed. Second, a diagnostic technology transfer framework is presented and supported by a review and synthesis of the relevant literature. Third, the relevant aims and methodology of a three year funded research project are articulated. Further, research findings are structured and analysed using the technology transfer framework. Finally, conclusions are drawn, and implications for theory and practice offered.

\section{nD modelling demystified}

2D and 3D modelling in the construction industry takes its precedence from the laws governing the positioning and dimensions of a point or object in physics whereby a three number vector represents a point in space, the $\mathrm{x}$ and $\mathrm{y}$ axes describing the planar state and the $\mathrm{z}$ axis depicting the height (Lee et al, 2003). 3D modelling in construction goes beyond the object's geometric dimensions and replicates visual attributes such as colour and texture. This visualisation is a 
common attribute of many architectural, engineering and construction design packages, such as 3D Studio Max (AutoDesk, 2005) and ArchiCAD (Graphisoft, 2005), which enable the simulation of design options.

Combining time sequencing in visual environments with the 3D geometric model $(x, y, z)$ is commonly referred to as 4D CAD (Rischmoller et al, 2000). Using 4D CAD, the processes of construction can be demonstrated before any real construction activities occur (Kunz et al, 2002). This will aid users to find the possible mistakes and conflicts at the early stage of design, and to predict the production schedule. Research projects around the world have taken the $4 \mathrm{D}$ concept and developed it further (for example, see Dawood et al, 2002, Kunz et al, 2002). Commercial 4D packages are also available, such as 4D Simulation from VirtualStep, Schedule Simulator from Bentley, and 4D CAD System from JGC Corporation (Emerging Construction Technologies, 2005).

$\mathrm{nD}$ modelling builds upon the concept of 4D modelling and aims to integrate an $n$th number of design dimensions into a holistic model, which would enable users to construct and visually project the building design over its complete lifecycle. $\mathrm{nD}$ modelling is based upon the building information model (BIM), a concept first introduced in the 1970s and the basis of considerable research in construction IT (information technology) ever since. The idea evolved with the introduction of object oriented CAD; the 'objects' in these CAD systems (e.g. doors, walls, windows, roofs) can also store non-graphical data about the building in a logical structure. The BIM is a repository that stores all the data 'objects' with each object being described only once. Both graphical and non-graphical documents, such as drawings and specifications, schedules and other data respectively, are included. Changes to each item are made in only one place and so each project participant sees the same information in the repository. By handling project 
documentation in this way, communication problems that slow down projects and increase costs can be greatly reduced (Cyon Research, 2003).

Leading CAD vendors such as AutoDesk, Bentley and Graphisoft have promoted BIM heavily with their own BIM solutions and demonstrated the benefits of the concept (Lee et al, 2002). However, as these solutions are based on different, non-compatible standards, an open and neutral data format is required to ensure data compatibility across the different applications. Industry Foundation Classes (IFC), developed by the International Alliance for Interoperability, provides such capabilities. IFCs provide a set of rules and protocols that determine how the data representing the building in the model are defined and the agreed specification of classes of components enables the development of a common language for construction. IFC-based objects allow project models to be shared whilst allowing each profession to define its own view of the objects contained in that model. This leads to improved efficiency in cost estimating, building services design, construction, and facilities management (FM). IFCs enable interoperability between the various AEC/ FM software applications allowing software developers to use IFCs to create applications that use universal objects based on the IFC specification. Furthermore, this shared data can continue to evolve after the design phase and throughout the construction and occupation of the building.

The 3D to $\mathrm{nD}$ research project at the University of Salford developed a holistic $\mathrm{nD}$ modelling tool using IFCs, to help improve the decision-making process and construction performance by enabling true 'what-if' analysis to be performed to demonstrate the real cost in terms of the variables of the design issues (Lee et al, 2002). The resultant model allows trade-offs between the parameters to be clearly envisaged, so as to satisfy the various project stakeholders. The $\mathrm{nD}$ 
modelling project developed a tool to incorporate 5 design perspectives in order to systemically assess and compare the strengths and weaknesses of different design scenarios; namely:

- Determine cost options

- Maximise sustainability

- Examine people’s accessibility

- Incorporate crime deterrent features

- Analyse the building's acoustics

The system architecture, depicted in Figure 1, consists of two primary components:

- An $\mathrm{nD}$ knowledge base platform that provides analysis functionality of design information related to the various design perspective constraints of the $\mathrm{nD}$ modelling. Figure 2, for example, shows a screenshot of accessibility analysis.

- A decision support system employing a multi-criteria Analytic Hierarchy Process (AHP) which supports a combined assessment of qualitative criteria and quantitative criteria. Figure 3 provides a screenshot of the AHP technique for determining suitable building materials in accordance with prescribed lifecycle costing, acoustic and environment impact considerations. 


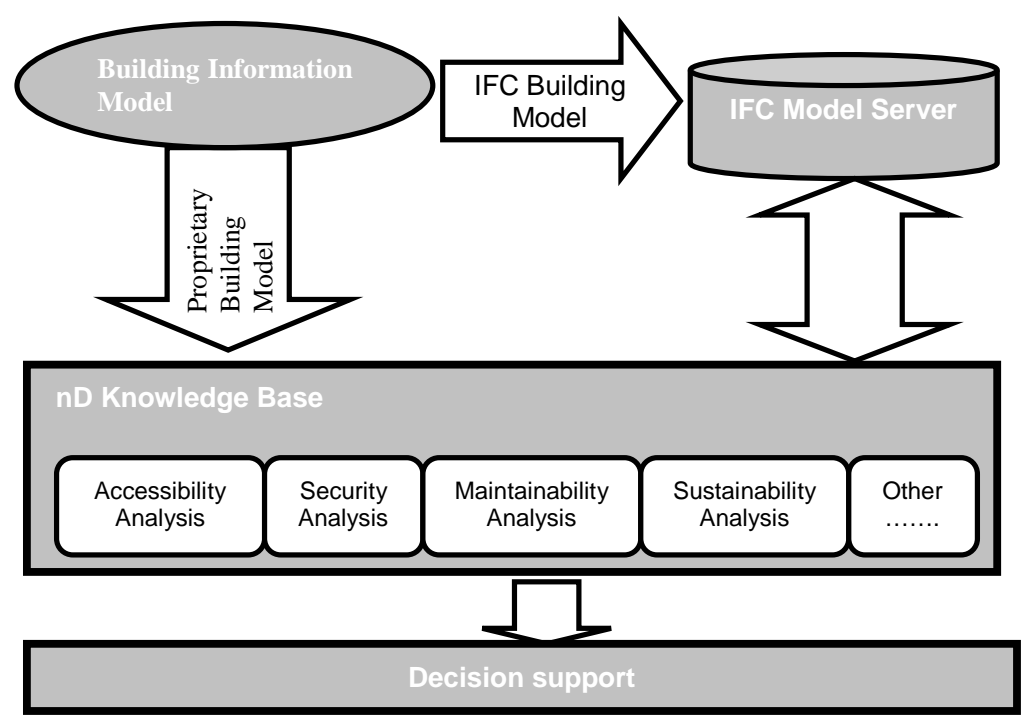

Figure 1: System architecture of the $\mathrm{nD}$ modelling prototype tool

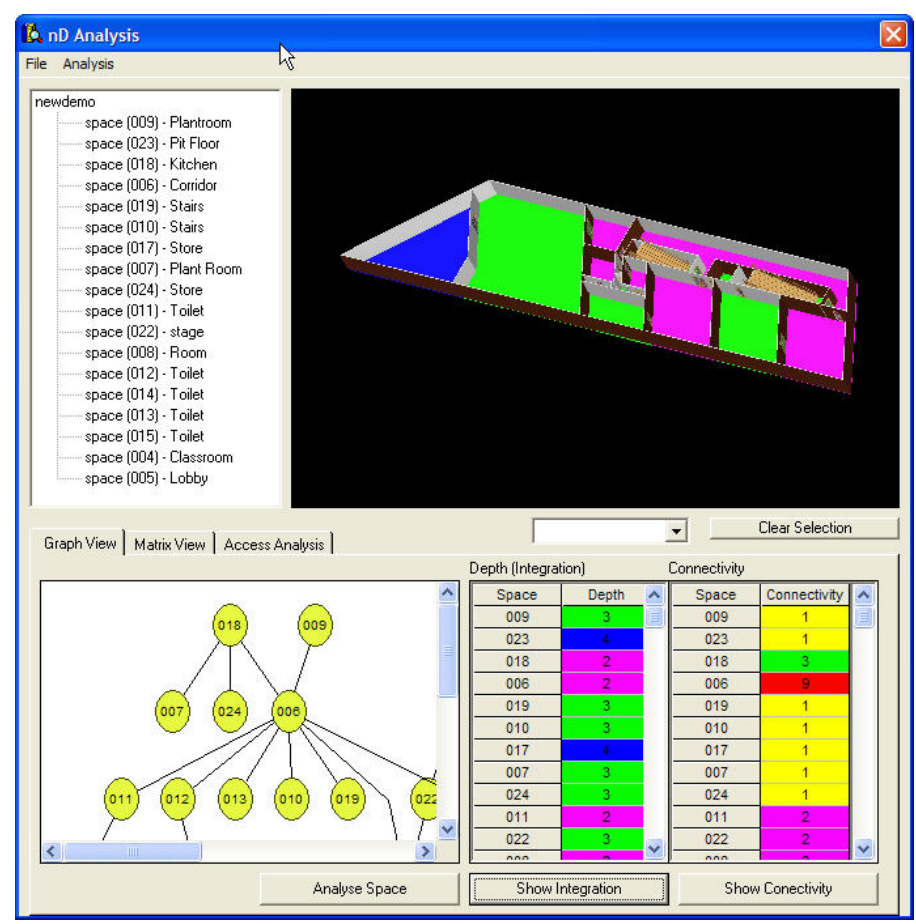

Figure 2: Screenshot of nD prototype tool, displaying accessibility analysis 


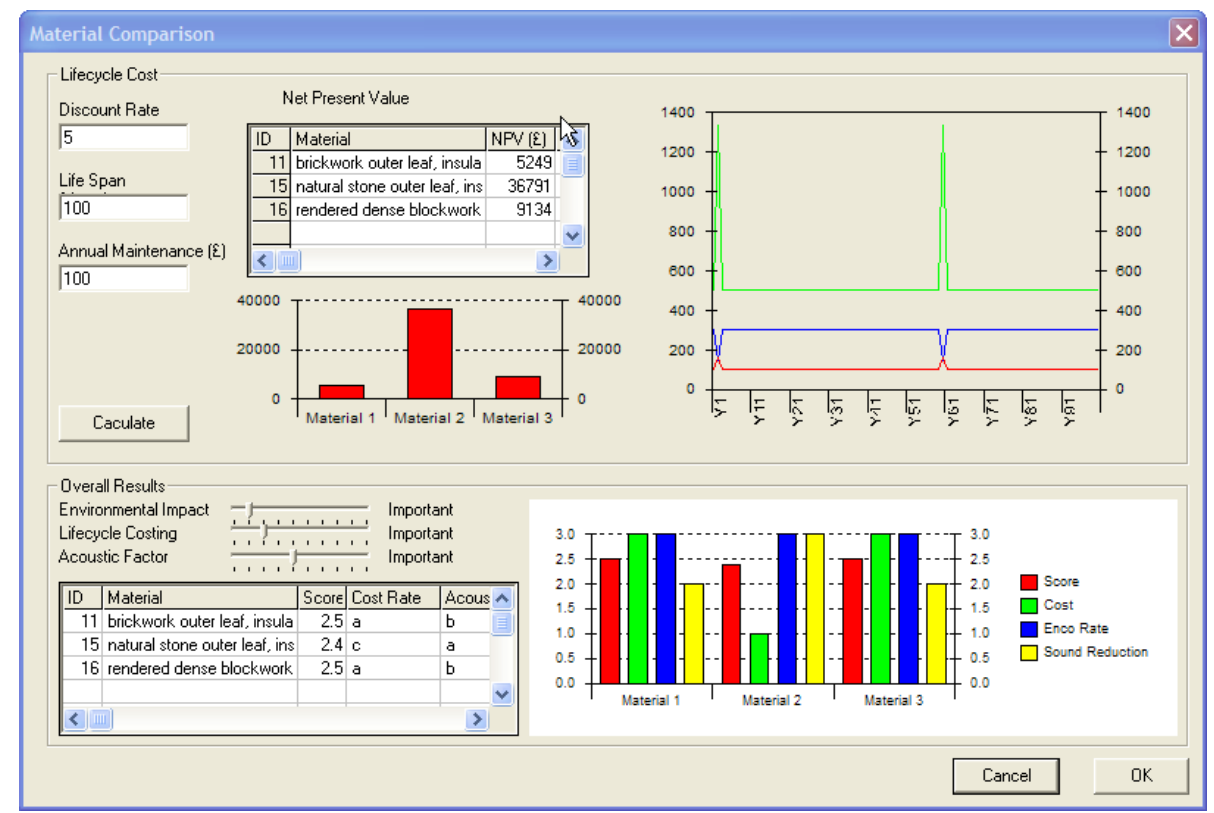

Figure 3: Screenshot of the AHP functionality of $\mathrm{nD}$ prototype tool

A full description of the $\mathrm{nD}$ tool can be found in Lee et al (2003). The discussion so far has presented the $\mathrm{nD}$ tool and its perceived benefits. The normative benefits, however, does not automatically equate to its actual adoption and use in industry. To gain a better understanding of the drivers and barriers to adoption, an appreciation of technology transfer issues is required.

\section{The 'technology transfer system' model}

Performance improvement based on construction research and innovation absorbed into companies through technology transfer, can and does, occur successfully. However, present construction industry technology transfer endeavours are being severely hampered by a lack of understanding of technology transfer processes and their interrelationships to both company 
capabilities and processes, and the knowledge characteristics of the technologies being transferred:

- First, current approaches tend to view technology transfer as a mechanistic 'pick-andmix' exercise - identifying new technologies, and trying to insert them in their existing form into (unsurprisingly) unreceptive construction companies (Barrett and Sexton, 1999).

- Second, current technology transfer mechanisms are not sufficiently informed by, or engaged with, company strategic direction and organisational capabilities and processes necessary to enable them to absorb technologies and to turn them into appropriate innovations. Experience from the manufacturing sector, for example, has stressed that the capacity of companies to understand and effectively use new technologies from external sources is heavily influenced by the level of prior-related knowledge and expertise (for example, see Adler and Shenhar, 1993).

- Finally, current technology transfer mechanisms do not fully appreciate that both the ability and motivation for companies to absorb and use new technology is significantly influenced by the knowledge characteristics of the technology. Grant and Gregory (1997), for example, concluded from an investigation of manufacturing technology transfer that the extent of the required tacit knowledge to absorb and use manufacturing technology had a significant impact on the success of the transfer. 'Hard' technologies which are characterised by explicit knowledge require very different diffusion mechanisms and organisational capabilities and processes than those required for 'soft' technologies which are tacit in nature. 
The interactive nature of these elements stresses the systemic nature of technology transfer, and can be fruitfully viewed as a 'technology transfer system' made up of inter-organisational networks, organisational direction and capability, and knowledge characteristics of technology. This more fluid, dynamic view of technology transfer is consistent with the move away from traditional, sequential models of innovation and technology transfer (Van de Ven, et al., 1999). This position reconceptualises the technology transfer phenomenon from a simple cumulative sequence of stages or phases, to multiple progression of divergent, parallel and convergent paths, some of which are related and cumulative, and others not. The argument is that technology transfer will only be effective if all three elements are appropriately focussed and integrated to achieve a specific aim. The three elements of the ‘technology transfer system’ will are discussed in more detail below.

\section{Organisational direction and capability}

The motivation and ability of companies to absorb and innovate from new technologies has to come from within the company: through envisioning technology strategies and supporting organisational capabilities. Technology is a crucial strategic variable in creating competitiveness; indeed, the connection between technology and corporate strategy is confirmed as 'increasingly managers have discovered that technology and strategy are inseparable' (Kantrow, 1980: 4). The technology strategy of a company should address the issues of acquiring, managing and exploiting technologies which progress corporate aspirations (Clarke, et al., 1989). An appropriate focus for a company's technology strategy can be usefully considered as the generation of a balanced portfolio of enabling, critical and strategic technologies. Enabling technologies are classified as those technologies which are necessary at a functional level for the company's survival, and are widely available to all competitors in the 
construction industry. Critical technologies are viewed as those technologies which are unique to the company, and which give the company a differentiated technology over its existing and potential competitors. The acquisition and exploitation of enabling and critical technologies are in the domain of the company's short- to medium- term technology strategy. Strategic technologies are those technological trajectories pursued by a company that they anticipate (through technological and market forecasting) to become the critical technologies of the future. Strategic technologies, by their intrinsic nature, are in the domain of the company's long-term technology strategy.

The motivation and capacity of firms to innovate and to absorb and use new technology are very much shaped by general business and project environments. Research in innovation in small construction companies, for example, concludes that there are two principal modes of innovation: mode 1 and mode 2 (Sexton and Barrett, 2003). Mode 1 innovation focuses on progressing single project, cost-orientated relationships between the client and the firm - this mode of innovation is more driven by rapid change and uncertainty in the interaction environment. (The interaction environment is that part of the business environment which firms can interact with and influence.) Mode 2 innovation concentrates on progressing multiple project, value-orientated relationships between client and the firm - this mode of innovation is more aligned to improving the effectiveness of a firm's relationship with its clients. The mode of innovation is substantially determined by the nature of the interaction environment: an enabling interaction environment encourages Mode 2 innovation; and a constraining environment is conducive to Mode 1 innovation. An enabling interaction environment is one which the firm can influence to a significant extent, enabling the firm to innovate within a longer term and more secure context. A constraining interaction environment is one which a 
small construction firm can only influence to a limited extent, constraining the firm to innovation activity undertaken within a shorter and more insecure context.

Coupled with strategic direction and business context, companies need the organisational capability to absorb and use new technology. This capability is influenced by the level of priorrelated knowledge and expertise (i.e. basic skills, shared language, technological acumen) that exist in the organisation (Cohen and Levinthal, 1990). Thus, it is clear that organisations will not be able to accomplish many of their key strategic and operational goals for technology transfer without adequate complementary capabilities (for example, see Bröchner, et al., 2004; Adler and Shenhar, 1993).

\section{Inter-organisational networks}

Companies do not operate in a vacuum; rather, they are situated in a number of fluctuating inter-organisational networks of varying complexity (Bresnen and Marshall, 2000a, 2000b, 2000c; Betts and Wood-Harper, 1994). Inter-organisational networks promote and facilitate the development and exchange of knowledge and resources needed to encourage learning and innovation in participating companies (for example, see Barlow and Jashapara, 1998; Ebers, 1997; Grandori and Soda, 1995). Indeed, it has been argued that the greater the number of interorganisational networks that a company is involved in, the greater the likelihood of generating and supporting successful innovation (for example, see Ahuja, 2000; Porter, 1990).

There are two main types of inter-organisational network. First, companies are exposed to 'business networks' through their normal client and supply chain interaction. These networks can encourage innovation because the companies involved are able to share needed expertise 
and resources (Hauschlidt, 1992). Indeed, the knowledge necessary for innovation processes is often created at the interfaces of business network technology transfer. The innovation process is therefore in part a knowledge and technology mobilisation process, based on intensive social and economic interaction processes (Hakansson, 1987). Second, companies are embedded, to vary degrees, in 'institutional networks', such as educational institutions, government bodies, research institutions and professional associations. Such networks are also potentially useful in providing companies with the knowledge and expertise needed for innovation (for example, see Abbott, et al., 2004; Hauschlidt, 1992). Professional associations, for example, disseminate a particular body of knowledge to industry via their members, and thus act as vehicles for the diffusion and translation of knowledge needed for innovation (Constrinnonet, 2004; Allen, 1977).

\section{Knowledge characteristics of technology}

Technology is not transferred as a self-contained artefact; rather, for success, the technology and the knowledge of its use and application must be transferred (for example, see Sahal, 1981). The extent to which new technology can be effectively absorbed by construction companies is thus substantially influenced by the knowledge characteristics of the technology being transferred. Two characteristics are especially important. The first is the extent to which the knowledge embodied in the technology is explicit or tacit. Tacit knowledge is hard to formalise, making it difficult to communicate or share with others. Tacit knowledge involves intangible factors embedded in personal beliefs, experiences and values. Explicit knowledge is systematic and easily communicated in the form of hard data or codified procedures. Often there will be a strong tacit dimension with how to use or implement explicit knowledge (for example, see Nonaka and Takeuchi, 1995). The second characteristic is complexity. Whether based on 
explicit or tacit knowledge, some technologies are just more complex than others. The more complex a technology, the more difficult it is to unravel (for example, see Gibson and Smilor, 1991).

In summary, the knowledge conversion concept argues that technology transfer is a social process of interactive learning within and between inter-organisational networks, from which a shared language of tacit and explicit knowledge can be developed.

\section{Research methodology}

The aim of the 3D to $\mathrm{nD}$ modelling project was not only to develop a prototype tool, but also to exploit the technology and evaluate potential industry adoption by addressing technology transfer issues. This paper concentrates on the latter objective by investigating the drivers and barriers to industry adoption.

The research methodology was designed to develop a greater understanding of the absorption and use of $\mathrm{nD}$ modelling in construction companies. The primary data was from fifteen semistructured interviews with key staff from eleven construction companies comprising of architects, contractors, specialist consultants and engineers. The organisations were selected at random from participants of a construction IT seminar held by the University of Salford; all were SMEs and their involvement/ understanding of BIM varied from none/ little to a great awareness -6 of the survey organisations were primarily working with 2D drawings, 7 of the survey organisations were working with 3D drawings, and the remaining 2 organisations were utilising 3D models (although these were not BIM models). The survey organisations were considered to be 'interested' in construction IT through attending the seminar, but were not 
aware of $\mathrm{nD}$ technology. In this way, the results were thought to demonstrate the views of the majority of the industry as opposed to large organisations whom are usually considered to be IT innovators/ adopters. In each case, the researcher visited the organisation and demonstrated the $\mathrm{nD}$ tool to a number of staff within a workshop environment. The participants were then free to discuss and utilise the tool at their leisure. The researcher returned to the organisation several days later to conduct the evaluative semi-structured interview.

A semi-structured interview approach was taken for the data collection to provide both the stability to follow a predetermined route of enquiry, and the flexibility to probe further where the interviewee felt that supplementary information was valuable to bring new insights into the discussion, or to amplify answers in response to preset questions.

The semi-structured interview was shaped by the questions: what are the benefits of the technology: who would use the technology? where would they use the technology? and when in the design process would the $\mathrm{nD}$ modelling technology be used? The results are structured around the context of the technology transfer system, as previously described.

\section{Results and analysis}

\section{Organisational direction}

$\mathrm{nD}$ modelling technology was generally seen as potentially useful by architects but, at present, not sufficiently proven to risk disrupting current ways of working and existing technology infrastructures. nD modelling technology was described by one architect, for example, as 
having potential to 'improve upon the exchange of construction information,' with the benefit being articulated by another architect as being 'the idea that the drawing is only ever produced once, and so mistakes made by copying the drawing is only ever produced once - this can happen with the mechanical and electrical engineers at times.' This potential benefit was conveyed by the contractors, with one commenting that ' $\mathrm{nD}$ seems to be a great prospect, especially if contractors can be involved in the design process. The design plans and elevations may be checked and checked, but there will always be problems with it. It is human nature that mistakes is made. We as contractors only find all of these mistakes once the building has been built. If there can be a checking mechanism, and a way in which we can get involved and see the designs first, I think problems will be minimised.’

The risk dimension, however, was stressed by both the contractors and the architects, with concern that nD modelling technology needed to be demonstrably proven to offer greater added value, compared to existing arrangements, before firms would be sufficiently motivated to adopt and use it. This view was captured in the argument that 'change takes time and costs a lot of money, so you would need to demonstrate the benefits of $\mathrm{nD}$ in terms of time, cost and quality before it would be widely adopted.' This generic view of risk was brought to life by an architect who asked, 'Who will own the drawings? How will risk be assigned? How does this impact upon professional indemnity? Unless the whole structure and legal system of the industry is changed, I cannot see how $\mathrm{nD}$ can be implemented soon.'

This position was reinforced by the view that the incumbent ways of working were widely understood and appreciated and that, according to one architect, 'we have a document management system in place, and it is ideal. It has speeded up the process of sending drawings 
and we, as a company, are happy with this. I think document management systems are more aligned to the way a construction project team works than the $\mathrm{nD}$ tool.'

\section{Inter-organisational networks}

There was consensus across the contractor and architect interviewees that the $\mathrm{nD}$ modelling tool needed to be appropriately integrated and mobilised through the supply chain if it was to generate the sustained impact to encourage widespread adoption and diffusion. The architects interviewed argued that the principal role of the $\mathrm{nD}$ modelling tool was in the design phase, with involvement from a number of project actors: 'this tool can only be used during the detailed design stage. It is during the early design stage where the architect experiments with the design of the building, and nothing should interrupt that process. Besides, the tool would be more useful to check conformity of regulations after the engineers have started to add to the design. We as architects are clear about regulations, and usually our designs conform to the majority of the regulations. It is when other engineers start to move things in the drawing around, and someone else wants to move something somewhere else, do things get complicated. Actually, in this instance I think the tool would really benefit our work.'

The need for project supply chains as a whole to adopt the technology was stressed, with one contractor articulating that, 'the tool will only be successful if everyone in the project supports and fully adopts it. It can only really work if it was an online tool, so that everyone could access the latest version of the model. I think that the client should own the design, as at the end of the

day, it is the client who is paying for the project. The client should own the design and not the architect. In this way, a shared product model can exist.' 


\section{Knowledge characteristics of the $\mathrm{nD}$ modelling technology}

The $\mathrm{nD}$ modelling tool's human computer interface was seen as important, with a contractor remarking that 'the tool seems to be user friendly and pretty self-explanatory.' The need for compatibility with existing design packages was noted, with one architect observing that: 'we can still use our own design packages and do not have to learn new ones. This is a great advantage and must not be overlooked. Architects really have to be specialists on a particular design package. If a new package is used, drawings take a lot longer which costs more money to us, and there is more chance of mistakes being made. And this is a bigger problem if you have to use another design package on another project - this can be very costly.'

In addition, the need for potential adopters to experiment with the new technology was noted. One architect, for example, emphasised that 'I need to have the opportunity to play about with the tool on my own, that is when you can assess how practical something is.' The theme of 'getting to know the technology' was continued into the required capability development after adoption, with a contractor remarking that, 'there needs to be training sessions delivered on the tool, so that people will adopt it ... without training, adoption will be sporadic.'

\section{Discussion/ Conclusions}

This paper explores the feasibility of industry absorbing and diffusing nD modelling technology by considering key technology transfer issues; namely organisational direction, interorganisational networks, and knowledge characteristics of technology. The results from 15 survey interviews indicate that construction professionals appreciate the potential significant benefits of $\mathrm{nD}$ modelling technology. The survey organisations were selected at random, all 
who had not previously adopted $\mathrm{BIM} / \mathrm{nD}$ modelling technology as to gain a representative view of potential $\mathrm{nD}$ modelling industry uptake. The findings reveal, however, that construction firms will only be motivated to absorb and use $\mathrm{nD}$ technology when the technology is sufficiently proven that it will contribute to the business in a quick, tangible fashion, and which can be dovetailed into organisational and technological capabilities they already possess. At present, $\mathrm{nD}$ modelling technology is seen as too embryonic; too far removed from construction firms' 'comfort zones'; requiring too much investment; and, containing too many risks.

The implication for practice is that firms need to incrementally adopt $\mathrm{nD}$ modelling in order to start realising the benefits. Indeed, the full benefits cannot be realised with this partial approach, in that buy-in from the entire construction project team is required. However, the implication is that it does not matter too much where a firm starts; the effect of $\mathrm{nD}$ modelling is likely to be widespread provided that a sustained effort is maintained. Thus, a firm can choose to start in an area that has particular importance for them and about which they can get highly motivated. The second aspect is the rate at which improvement is achieved. It seems clear that the gains of introducing $\mathrm{nD}$ are accumulated slowly. Those seeking to improve should be realistic and take an incremental approach that, again, starts somewhere and in due course makes significant progress, through sustained effort. The common core of the above two aspects is the need to start somewhere and then to maintain the effort. The initial focus for the improvement, or indeed the specific initiative used to kick off the process, are both clearly necessary in terms of gaining the commitment and enthusiasm from those involved, however, they are actually less important to the ultimate improvement gained than might be thought.

For policy makers, the results promote two fruitful areas for intervention. First, the need to support demonstration projects to illustrate and communicate the value of $\mathrm{nD}$ modelling to the 
sector as a whole. Second, to fund research into the areas of concern highlighted by the practitioners interviewed for this paper; in particular, e-legal issues related to data ownership.

In conclusion, $\mathrm{nD}$ modelling addresses a real need to identify and appropriately reconcile competing design criteria. The challenge for $\mathrm{nD}$ modelling technology, along with any new technology, is to shift from its 'technology push' emphasis to a more balanced 'market orientated' stance which allows the technology to be shaped by both strategic design concerns, and the rough and tumble of day-to-day operational needs. If this trajectory is pursued, $\mathrm{nD}$ modelling technology has a positive future.

\section{References}

Abbott, C., Ong, H.C. and Swan, W. (2004) A regional model for innovation and cultural change in the construction industry. Proceedings of Clients Driving Innovation International Conference Surfers Paradise, Australia, 25th - 27th October.

Adachi, Y. (2002) Overview of IFC Model Server Framework. In proceedings of the International ECPPM conference - eWork and eBusiness in Architecture, Engineering and Construction, Portoroz, Slovenia.

Adler, P.S. and Shenhar, A. (1993) Adapting your technological base: the organizational challenge. Sloan Management Review, 32, 25-37.

Ahuja, G. (2000) Collaborative networks, structural holes, and innovation: A longitudinal case study. Administrative Science Quarterly, 45, 425-455. 
Allen, T.J. (1977) Managing the Flow of Technology, MIT Press, Cambridge, MA.

Alshawi, M. \& Ingirige, B. (2003) Web-enabled project management: an emerging paradigm in construction. Automation in Construction, 12, 349-364.

Alshawi, M., Faraj, I., Aouad, G., Child, T. \& Underwood, J. (1999) An IFC Web-based Collaborative Construction Computer Environment. Invited paper, in proceedings of the International Construction IT conference, Construction Industry Development Board, Malaysia, 8-33.

Anumba, C.J., (1998) 'Industry uptake of construction IT innovations - Key elements of a proactive strategy', Proceedings of the CIB W78 Conference, Stockholm, Sweden: 3rd - 5th June.

Aouad, G., Sun, M. \& Faraj, I. (2002) Automatic generation of data representations for construction application. Construction Innovation, 2, 151-165.

AutoDesk (2005) www.autodesk.com/3dsmax Accessed April 12th.

Barlow, J. and Jashapara, A. (1998) Organisational learning and inter-firm partnering in the UK construction industry. Learning Organisation, 5, 86-98.

Barrett, P. and Sexton, M.G. (1999) The transformation of 'out-of-industry' knowledge into construction industry wisdom. Linking Construction Research and Innovation to Research and 
Innovation in Other Sectors, Construction Research and Innovation Strategy Panel, London, 24th June.

Betts, M. and Wood-Harper, T. (1994) Reengineering construction: a new management research agenda. Construction Management and Economics, 12, 551-6.

Boyd, D. (2001) e-science centre. Available on-line at http://www.e-science.clcr.ac.uk

Bozeman, B. (2000) Technology transfer and public policy: a review of research and theory. Research Policy, 29, 627-55.

Bresnen, M. and Marshall, N. (2000a) Partnering in construction: A critical review of issues, problems and dilemmas. Construction Management and Economics, 18, 229-237.

Bresnen, M. and Marshall, N. (2000b) Motivation, commitment and the use of incentives in partnerships and alliances. Construction Management and Economics, 18, 587-598.

Bresnen, M. and Marshall, N. (2000c) Building partnerships: Case studies of client-contractor collaboration in the UK construction industry. Construction Management and Economics, 18, 819-832.

Bröchner, J., Rosander, S. and Waara, F. (2004) Cross-border post-acquisition knowledge transfer among construction consultants. Construction Management and Economics, 22, 42127. 
Buchanan, D.A. and Boddy, D.: 1983, Organizations in the computer age, Gower, Hampshire.

Christiansson, P., Dalto, L., Skjaerbaek, J., Soubra, S. \& Marache, M. (2002) Virtual Environments for the AEC sector: The Divercity experience. In proceedings of the international ECPPM conference - eWork and eBusiness in Architecture, Engineering and Construction, Portoroz, Slovenia.

Clarke, K., Ford, D. and Saren, M. (1989) Company technology strategy. R\&D Management, $19,3$.

Cohen, W.M. and Levinthal, D.A. (1990) Absorptive capacity: a new perspective on learning and innovation. Administrative Science Quarterly, 35, 128-52.

Dawood, N., Sriprasert, E., Mallasi, Z. \& Hobbs, B. (2002) Development of an integrated information resource base for 4D/ VR construction processes simulation, Automation in Construction, 12, 123-131.

Derbyshire, A. \& Andrews, J. (1993) Crossing Boundaries. Construction Industry Council, London.

Drogemuller, R. (2002) CSIRO \& CRC-CI IFC Development Projects, ITM Meeting, Tokyo.

Durst, R. \& Kabel, K. (2001) Cross-functional teams in a concurrent engineering environment principles, model, and methods, in M.M. Beyerlein, D.A. Johnson, and S.T. Beyerlein, (eds), Virtual Teams, JAI, Oxford, pp. 167-214. 
Eastman, C., (1999) Building Product Models: Computer Environments Support Design and Construction, CRC Press LLC, Florida.

Ebers, M., (Ed.) (1997) The Formation of Inter-organisational Networks, Oxford University Press, Oxford

Egan, J., (1998) Rethinking Construction. Report form the Construction Task Force, (Department of the Environment, Transport and Regions, 1998).

Emerging Construction Technologies (2005) http://www.newtechnologies.org/ECT/Other/other.htm Accessed April 12th.

Emmerson, H., (1962) Studies of Problems before the Construction Industries, HMSO, London.

Fairclough, J., (2002) Rethinking Construction Innovation and Research: A Review of Government R \& D Policies, DTI: London.

Fischer, M., (2000) Construction Planning and Management using 3D \& 4D CAD models, Construction IT 2000, Sydney, Australia.

Gann, D. and Salter, A. (1999) Interdisciplinary skills for built environment professionals: A scoping study. Ove Arup, London. 
Gibbons, M., Limoges, C., Nowotny, H., Schwartzman, S., Scott, P. \& Trow, M. (1994) The new production of knowledge. Sage, London.

Gibson, D.V. and Smilor, R. (1991), Key variables in technology transfer: A field-study based empirical analysis. Journal of Engineering and Technology Management, 8, 287-312.

Grandori, A. and Soda, G. (1995) Inter-firm networks: antecedents, mechanism and forms. Organization Studies, 16, 183-214.

Grant, E.B. and Gregory, M.J. (1997), Tacit knowledge, the life cycle and international manufacturing transfer. Technology Analysis and Strategic Management, 9, 149-61.

Graphisoft (2003) The Graphisoft Virtual Building: Bridging the Building Information Model from Concept into Reality. Graphisoft Whitepaper.

Graphisoft (2005) www.graphisoft.com Accessed April $12^{\text {th }}$

Hakansson, H., (Ed.) (1987) Industrial Technological Development: A Network Approach, Croom Helm, London.

Halfawy, M., Froese, T., (2002) Modeling and Implementation of Smart AEC Objects: An IFC Perspective, CIB W78 Conference 2002 - Distributing Knowledge in Building, Denmark, 2002, 45-52. 
Hauschlidt, J., (1992), 'External Acquisition of Knowledge for Innovations - A Research Agenda’, R \& D management, 22: 105-110.

Howells, J. (1996) Tacit knowledge, innovation and technology transfer. Technology Analysis and Strategic Management, 8, 91-106.

Kantrow, A.M. (1980) The strategy-technology connection. Harvard Business Review, 58, 4.

Karola, A., Lahtela, H., Hanninen, R., Hitchcock, R., Chen, Q., Dajka, S., Hagstrom, K., (2002)

BSPro COM-Server - interoperability between software tools using industry foundation classes, Energy and Building 34 (2002) 901-907.

Khemlani, L., (2002), Architecture CAD: A Look Across the Spectrum, CADENCE, http://www.cadenceweb.com/2002/0102/coverstory0102.html

Kiesler, S., Siegel, J. \& McGuire, T.W. (1984) Social pyschological aspects of computermediated communication, American Psychologist, 39, pp1123-34.

Klien, G.A. and Crandall, B. (1991) Finding and using technology-specific expertise. Journal of Technology Transfer, 16, 23.

Kunz, J., Fischer, M., Haymaker, J., Levitt, R., (2002) Integrated and Automated Project Processes in Civil Engineering: Experiences of the Centre for Integrated facility Engineering at Stanford University, Computing in Civil Engineering Proceedings, ASCE, Reston, VA, 96-105, January 2002. 
Latham, M., (1994) Constructing the Team: Joint Review of Procurement and Contractual Arrangements in the UK Construction Industry. Department of the Environment, HMSO, 1994.

Lee, A, Marshall-Ponting, A., Wu, S., Koh, I., Fu, C., Cooper, R., Betts, M., Kagioglou, M. and Fischer, M., (2003) Developing a Vision of nD-enabled Construction, University of Salford: Salford.

Lee, A., Wu, S., Marshall-Ponting, A., Aouad, G., Tah, J. H. M. \& Cooper, R. (2005) nD Modelling - A Driver or Enabler for Construction Improvement? RICS Paper Series, 5(6), April.

Leibich, L., Wix, J., Forester, J., Qi, Z., (2002) Speeding-up the building plan approval - The Singapore e-Plan checking project offers automatic plan checking based on IFC, The international conference of ECPPM 2002 - eWork and eBusiness in Architecture, Engineering and Construction, Portoroz, Slovenia, 2002.

Leveson, R.K. (2003) Understanding interdisciplinarity as a paradox in construction professionalism, Proceedings of the CIB W78 Conference - Building Education \& Research (BEAR) vol 2, pp828-839, Salford Quays, Salford, UK, 8-11th April 2003. ISBN:1-900491-907

Luczak, H. (1998) Arbeitswissenschaft. Industrial engineering and economics, 2nd ed., Springer, Berlin. 
Mitropoulos, P. and Tatum, C.B. (2002) Technology adoption decisions in construction organizations. Journal of Construction Engineering and Management, 125, 5, 330-338.

Muir, T. \& Rance, B. (1995) Collaborative practice in the built environment. E \& FN Spon, London.

NAHB Research Centre, (2001) Commercialization of Innovations: Lessons Learned, NAHB Research Centre: Upper Marlborough.

Newell, S. \& Swan, J. (2000) Trust and inter-organizational networking. Human Relations, 53 (10), 1287-1328.

Nonaka, I. and Takeuchi, H. (1995) The Knowledge Creating Company: How Japanese Companies Create the Dynamics of Innovation, Oxford University Press, New York.

Payne, M. (2000) Teamwork in Multiprofessional Care. Palgrave, Basingstoke.

Porter, M. (1990) The Competitive Advantage of Nations, Free Press, New York.

Sahal, D. (1981), Alternative conceptions of technology. Research Policy, 10, 2-24.

Sauer, C., Johnson, K. Karim, K., Marosszeky, M. and Yetton, P., (1999) 'Reengineering the supply chain using collaborative technology: Opportunities and barriers to change in the building and construction industry', IFIP WG 8.2 New Information Technologies in Organisational Processes: Field Studies and Theoretical Reflections on the Future of Work, 
International Federation for Information Processing, Kluwer Publishers: University of Missouri, St. Louis: 21st - 22nd August.

Sexton, M.G. and Barrett, P., (2004) 'The role of technology transfer in innovation within small construction firms', Engineering, Construction and Architectural Management, Vol. 11, No. 5, pp. 342-348.

Sexton, M.G. and Barrett, P.S. (2003) Appropriate innovation in small construction firms. Construction Management and Economics, 21 (6) 623-33.

Stahl, J., Luczak, H., Langen, R., Weck, M., Klonaris, P. and Pfeifer, T.: 1997, Concurrent engineering of work and production systems, European Journal of Operations Research, 100, 379-398.

Stansfield-Smith, C. (1999) Review of architectural education - consultation working document. RIBA, London.

Stevens, C. (1996) The knowledge-driven economy. OECD Observer, 200, 6-11.

Teece, D. (1977) Technology transfer by multinational firms: The resource cost of transferring technological know-how. The Economic Journal, 87, 242-61.

Van de Ven, A.H., Polley, D.E., Garud, R, and Venkataraman, S. (1999) The Innovation Journey Oxford University Press, New York. 
Watts, C. (2000) Issues of professionalism in Higher Education, in Nicol, D. \& Pilling, S. (eds) Changing architectural education: towards a new professionalism. E \& FN Spon, London.

Yu, K., Froese, T., Grobler, F., (2000) A development framework for data models for computer-integrated facilities management. Automation in Construction 9 (2000) 145-167. 